\title{
How Do the Evolution and Innovation of Social Network Analysis Matter to Computer Science and Communications?
}

\author{
Romana Xerez \\ School for Social and Political Sciences, Technical University of Lisbon, Lisbon, Portugal \\ Email: kr rxerez@iscsp.utl.pt
}

Received May 17, 2013; revised June 20, 2013; accepted July 8, 2013

Copyright (c) 2013 Romana Xerez. This is an open access article distributed under the Creative Commons Attribution License, which permits unrestricted use, distribution, and reproduction in any medium, provided the original work is properly cited.

\begin{abstract}
This paper provides a comprehensive overview of evolution and innovation in social network analysis to the paradigm of social networking. It explains how the development of sociological theory and the structural properties of social groups matter to computer science and communications. Authors such as Moreno, John Barnes and Harrison C. White provide evidence of a growing body of literature addressing the networking of people, organizations and communities to explain the structure of society. This perspective has passed from sociology to other fields, changing understandings of social phenomena. Social networks remain a potent concept for analyzing computer science and communications. This paper shows how and why this has occurred and examines substantive areas in which social network analysis has been applied-mainly how the advantages of graphic visualization and computer software packages have influenced SNA in different audiences and publics leading to the unfolding of social networking to different audiences and publics.
\end{abstract}

Keywords: Social Network Analysis; Theory; Paradigm; Software

\section{Introduction}

Social network analysis (SNA) has been growing as an interdisciplinary field grounded in sociology. After the 70 s this seminal paradigm developed significant research, methods and theory that have increased traditional sociological perspectives. After four decades of more "hidden" and isolated research the network perspective emerged and proved how networks are significant in society. The increasing contribution of anthropological and physics perspectives have been decisive to the emergence of SNA. The value of networks is one of the most relevant sociological contributions to science, as well as society. The social networks score has proved the relevance of the sociological context in economics, politics, health, communication, computer science, democracy and terrorism. This paper explores the value of the development of social networks to applications in information science and communication.

\section{History: The Emergence of Social Networking Perspectives and Key Concepts}

This simple idea of a network (graph) — which is a set of points through which a number of groups of lines link points-gave rise to the use of social networking as a way to provide important structural information about the patterns of social connections. SNA is based on the relevance of the network to society as it studies the relational interaction between people, organizations, groups and communities, as well as its structure. It assesses how distributing scarce resources constrains the behaviour of individuals and enhances social change through the use of qualitative and quantitative methods.

According to Freeman [1], the organization of SNA as a research paradigm has four relevant aspects: the analysis of social networks 1) is driven by intuition based on the narrow links of the social; 2 ) is based on the systematization of empirical data; 3) is strongly built from the graphic imagery; 4) is dependent on the use of computational and/or mathematical models. It is precisely the diversity of empirical applications that has encouraged its growth and interdisciplinary perspective.

The beginning of analysis of social networks dates back to the origin of sociology. The first sociological interpretations can also be regarded as the beginning of an embryonic analysis of social networking. The first analysis of social networks was conducted at the end of 
the nineteenth century, when Auguste Comte proposed an interpretation of society through the inter-relationships between social actors. As many nineteenth-century sociologists, such as Durkheim, Ferdinand Tönnies, Simmel and Spencer, shared this view, it represented the genesis of SNA.

The empirical research produced in the late nineteenth century proposed a graphical representation of great scientific interest, but most defenders located the beginning of the analysis of social networks in the 30s, with Moreno [2].

\subsection{Moreno and Sociometry}

Jacob Moreno, psychiatrist, was the author of pioneering experimental research and the founding father of sociometry. Moreno began by analyzing a set of people and relationships, which might or might not be linked, and collected data that allowed him to build pictures of the possible connections between all elements. He used items (nodes) to represent each person when there was a relationship between people and created a line (connection) between them. This simple idea of a network (graph), which is a set of points through which a number of groups of lines link, gave rise to the use of networks as a way to provide important structural information about the patterns of social connections. His discovery was soon used in research and attracted the attention of the scientific community and audiences outside academia.

While many of Moreno's ideas were well within the realms of social network analysis, its dissemination and development were carried out three decades later, in the 60s and 70s, by other authors such as Harrison C. White and Linton Freeman.

\subsection{MIT and Experimental Research}

In the 40s, one of the scholars who contributed to the development of network analysis was Kurt Lewin. He initially developed his field theory at Cornell University, and in 1945 founded the Research Centre for Group Dynamics at MIT, relocated to Michigan in 1948. This period also included the studies of Cartwright, Bavelas and Leavitt.

Leavitt's experimental research with 100 male students at MIT revealed four main types of communication: circle, chain, $\mathrm{Y}$ and wheel [3]. Each network node is a person, and the connection is communication. The central nodes of each figure are identified by higher centrality indices. The graphical representation of communication standards and research into centrality influenced the subsequent development of network analysis.

\subsection{The Manchester School and the Emergence of the Social Network Concept}

In the 20s and 30s, the progression of British social an- thropology owes much of its work to leading anthropologists such as Malinowski and Radcliffe-Brown. In 1914, Malinowski left the London School of Economics for Papua New Guinea, where he devoted himself to extensive field work that would lead to the Trobriand Islands [4]. Radcliffe-Brown, who was influenced by the work of Durkheim, investigated the importance of social relationships at length. He argued that a particular social relationship between two people exists only as part of a wider network of social relations involving many other people, and it is this network that is the subject of your research [5].

A key contribution to the development of SNA was the foundation of the Department of Social Anthropology and Sociology in 1949 at the University of Manchester, with Max Gluckman. A dynamic set of researchers: J. Clyde Mitchell, John Barnes, Siegfried Nadel and Elizabeth Bott. Bott studied [6] social integration by calculating the density of the network, though the social network concept is undoubtedly associated with John Barnes, who coined it in 1954 [7].

The first anthropological research on the network concept analyzed the exodus of rural peasants to cities. It showed that they continued to maintain strong social networks with relatives who had remained in their villages of origin, as well as their new urban networks. These complex social networks consisting of urban and rural links helped them obtain resources from the countryside and the city, which allowed them to face the new challenges of urban life.

\subsection{The Harvard Network and the Emergence of SNA}

The contribution of Harvard University to the study of social networks started in the 20s and is associated with the Harvard Graduate School of Business Administration and the work of Lloyd Warner and Elton Mayo. Despite the diversity of the research carried out in the 20s and 30 s, the analysis of social networks was still far from emerging.

\section{Harrison C. White and the Construction of Network} The Department of Sociology at Harvard University was founded in the 30s and gained a reputation due to the contributions of Talcott Parsons. The arrival of Harrison C. White marked an entirely new direction for sociology. White's work in collaboration with his students is regarded as one of the most important advances in social networks analysis, the White school [8], the emergence of Harvard [9] and the rebirth of Harvard [10].

White's course, Introduction to Social Relations 10, known as SR10, became a kind of Mecca that often received students from other backgrounds who wanted to attend his classes [11]. More than an introduction to so- 
ciology, the course was a forum where he led an entirely new sociological perspective. The foundations of network analysis were introduced by White, class after class, with new methods and the emergence of a new theory. The novelty of his ideas, concepts and teachings inspired great debates, with few references to sociologists, where students were expected to interpret social situations and develop mathematical models. Some figures introduced concepts.

White was responsible for developing a paradigm that formed the basis of the SNA that would be recognized among social scientists at the end of the 70s. A strong core of $\mathrm{PhD}$ students invested in determining the social networks analysis: Peter Bearman, Paul Bernard, Phillip Bonacich, Ronald L. Breiger, Kathleen M. Carley, Ivan Chase, Bonnie Erickson, Claude S. Fischer, Joel Levine, Siegwart M. Lindenberg, Michael Schwartz, Ronald Breiger, Christopher Winship, Barry Wellman and Mark Granovetter. These are the names of some of the students who joined White's group and contributed to the development of SNA for over three decades. The Harvard students are particularly prominent in the link between social network analysis and different scientific fields, such as, urban sociology (Barry Wellman), economic sociology (Mark Granovetter), health (Peter Bearman) and mathematical sociology (Phillip Bonacich). With his group of doctoral students in the Department of Sociology, he lent a striking new perspective to the development of sociology. It was about networks rather than concepts, representation and methodologies. At Harvard, White created a network of people around the same paradigm: social network analysis.

\subsection{The Social Value of Networks}

Social capital, the value of social networks, is one of the most discussed concepts in social sciences and has crossed the frontiers of academia and achieved something rare by coming into everyday life. One of the first reference to social capital was made by Lyda Judson Hanifan in 1916. She introduced the idea to highlight the importance of community involvement at successful schools. However, the concept of social capital only became widely used in the 1980s with Bourdieu, when it quickly became central to sociology and political science.

In 1998, SOCNET, a network for online discussion of social networks, sparked a debate about the genesis of the concept of social capital [12], after which it was established that social networks in cities had been the great promoters of the discussion that led to the dissemination of the concept in the 60 s.

Bourdieu [13] introduced the concept of social capital in sociology. It was mentioned in an article written in
French, which may explain the "silence" surrounding his work for some time. It was only some years later with the publication of Bourdieu's article in English [14] and then with the work of Coleman [15] that the sociological discussion of social capital really opened up. Political scientist Robert Putnam [16] at Harvard University took a central position in discussions of social capital. His idea was based on the principle that social networks had value. He examined the decline in bowling games and found that despite the increasing popularity of this American game people were bowling less. This reflected a change in the country that corresponded to a drop in the standard of living and the collapse of civic institutions and community life.

Although the idea of the collapse of American community life was the central theme of Putnam's work, not all researchers agreed with his conclusion. Paxton analyzed statistics on social capital in the United States and concluded that the results did not support Putnam's theory. He upheld that capital was not in decline in individuals, organizations or institutions [17]. Fischer also pointed out reasons for disagreeing with Putnam, particularly in the interpretation of social capital and argued that the decline was not constant in all the indicators and that, although many details of political involvement showed a decline, those on sociability proved to be inconsistent [18].

\subsection{The Small World Experiment}

All of us have had the experience of knowing someone who knows someone else who is a friend, family member or neighbour...the other person did not have the faintest idea. This experience often makes us say "It's a small world!" and this reflects the nature of social networks. Stanley Milgram asked the following question: how likely is each of us to find someone who does not know us but who knows someone who knows us? This gave rise to his famous experiment known as the small-world experiment. His research was conducted in two U.S. cities Wichita (Kansas) and Omaha (Nebraska). In Omaha letters were delivered to 160 people (people of departure) and each of them was asked to re-send the letter to a friend or acquaintance that he or she thought would send to the final destination (one goal)-broker in Boston. Of the initial 160 letters sent in Nebraska, 126 went astray and 44 reached their destination. The research concluded that the maximum number of contacts needed to know the other person was six, i.e. people were separated by "six degrees". The results revealed that the world was indeed very small and a connection to another person also allows access to their resources [19].

Although it has been criticized, Milgram's experiment led to new areas of research in social networks and a 
broad discussion of the "small world problem" emerged. A new generation of the study was conducted by Duncan Watts. He had a background in physics, was a professor of Sociology at Columbia University and recently principal researcher at Microsoft Research. Watts studied the dynamics of social networks and the results confirmed Milgram's theory. This recent small world experiment used the Internet [20]. The result showed that over 60,000 e-mails reached 18 people in 13 target countries, through referrals from friends or acquaintances. Researchers concluded that, on average, there were six intermediaries between two people who did not know each other. The results can be applied to social networks: the spread of a disease, a rumour, the structure of organizations, etc. These recent investigations into the "small world problem" also resulted in the enlargement of the already fuzzy, inclusive area of social network analysis, looking ahead to new, interesting applications, such as software tools.

\section{Linking Social Networks and Information Science: The Emergence of Software Tools}

Improvements in the paradigm of social networking, benefits to the integration and development of concepts such as centrality, star, reciprocity, heterogeneity, bonding, bridging, embeddedness, density, homophily, heterophily and many others have allowed social analysts to develop programs. In addition to the development of statistics and mathematics inherent in these concepts [21], the representation and visualization of networks made a great contribution to the progress and dissemination of this area and spread to different scientific fields.

Development of the inaugural program began in the 70s. The first, structure, came from Roland Burt in 1975. Later on came the GRADAP program, designed in 1988 to be compatible with the SPSS. A new phase with UCINET, which allowed wide dissemination of this area and it is now one of the most commonly used programs, currently in its sixth version. It was developed by a group of network analysts at the University of California, Irvine: Linton Freeman first, then Steve Borgatti and Martin Everett. One of the oldest network analysis programs is NEGOPY, developed in the late 70s. SIENA is a program for statistical analysis of social networks and its structure facilitates longitudinal studies, i.e. the analysis of the evolution of networks over time. Tom Snijders is one of the developers of the program and this perspective of social networks. Pajek was developed by Vladimir Batagelj and Andrej Mrvar in 1996. The capabilities of the program, especially in terms of graphics, have been important to its rapid growth. More recently, Steve Borgatti, one of the most renowned names in this area and one of the authors of Ucinet, netdraw.exe, developed the tool that is widely known and whose connection to Ucinet offers advantages. Besides these, there were other programs such as NetMap for network analysis using Excel, Network Genie, or CiteSpacer. Others are being developed, as is the case of SPAN by James Moody.

\section{Conclusions}

Although the first sociological interpretation of society in terms of relational perspective was developed in the late nineteenth century, the emergence of SNA as a scientific paradigm is recent. Moreno's work in sociometry, the contributions made by Harvard University and in particular the work of Harrison White from the 60s onwards and the role of the University of Manchester was important roots of SNA. Sociology, anthropology, mathematics, physics and other interdisciplinary natural and social sciences explain SNA's emergence in the mid 70s. The development of software packages has also been central to the emergence of the social networking paradigm more recently.

The importance of links between social actors transcribed in empirical data and the importance of graphics make it advantageous for scientific research in very different areas. The areas of application are numerous given the importance and strong growth of social networking sites on the internet, the diversity of specific software for data processing of social networking, the ease of representing networks, the variety of research areas in which social network analysis can be instrumental and more recently the interest shown by social capital have contributed to marked growth in this area. The representation and visualization of networks made a great contribution to the development and dissemination of this area, transposing it to different scientific fields. The evolution of the social networking paradigm has contributed to the integration and development of concepts such as social capital and small world. In this context, it should provide for continued application to new areas and expansion at either empirical or theoretical level in fields such as terrorism [22], optimism [23] and computer mediated communication [24].

\section{REFERENCES}

[1] L. Freeman, "The Development of Social Network Analysis,” Empirical Press, Vancouver, 2004.

[2] J. Moreno, "Who Shall Survive? Foundations of Sociometry, Group Psychotherapy and Sociodrama,” Beacon House, Washington DC, 1934.

[3] H. J. Leavitt, "Some Effects of Communication Patterns on Group Performance,” Journal of Abnormal and Social Psychology, Vol. 1, No. 46, 1951, pp. 38-50. doi:10.1037/h0057189

[4] B. Malinowski, "Argonauts of the Western Pacific," 9th 
Edition, Routledge, London, 2002.

[5] A. Radcliffe-Brown, “On Joking Relationships,” Journal of the International African Institute, Vol. 3, No. 13, 1940, pp. 195-210. doi:10.2307/1156093

[6] E. Bott, "Family and Social Network," Tavistock, London, 1957.

[7] J. Barnes, "Class and Committees in a Norwegian Island Parish,” Human Relations, Vol. 7, No. 1, 1954, pp. 39-58. doi:10.1177/001872675400700102

[8] M. Santoro, "Framing Notes. An Introduction to Catnets," Sociologica, No. 1, 2008, pp. 1-20.

[9] J. Scott, "Social Network Analysis: A Handbook," Sage, London, 2001.

[10] L. Freeman, "The Development of Social Network Analysis,” Empirical Press, Vancouver, 2004.

[11] M. Schwartz, “A Postscript to Catnets,” Sociologica, No. 1, 2008, pp.1-5.

[12] S. Borgatti, "A SOCNET Discussion on the Origins of the Term Social Capital,” Connections, Vol. 2, No. 21, 1998, pp. 37-46.

[13] P. Bourdieu, "Le Capital Social: Notes Provisoires," Actes de la Recherche en Sciences Sociales, Vol. 31, No. 1, 1980, pp. 2-3.

[14] P. Bourdieu, “The Forms of Social Capital," In: J. G. Richardson, Ed., Handbook of Theory and Research for the Sociology of Education, Greenwood Press, New York, 1986, pp. 241-258.

[15] J. Coleman, "Social Capital in the Creation of Human Capital,” American Journal of Sociology, Vol. 94, 1988, pp. 95-120. doi:10.1086/228943

[16] R. Putnam, “Bowling Alone: America’s Declining Social
Capital,” Journal of Democracy, Vol. 1, No. 6, 1995, pp. 665-678.

[17] P. Paxton. "Is Social Capital Declining in the United States? A Multiple Indicator Assessment,” American Journal of Sociology, Vol. 1, No. 105, 1999, pp. 88-127. doi:10.1086/210268

[18] C. Fischer, "Review of Bowling Alone: What's the Score?” Social Networks, Vol. 2, No. 27, 1999, pp. 55-167.

[19] S. Milgram, “The Small-World Problem," Psychology Today, Vol. 1, No. 1, 1967, pp. 60-67.

[20] D. Peter, S. Muhamad and D. Watts, "An Experimental Study of Search in Global Social Networks," Science, Vol. 301, No. 5634, 2003, pp. 827-829.

[21] P. Bonacich, "Factoring and Weighting Approaches to Status Scores and Clique Identification,” Journal of Mathematical Sociology, Vol. 2, No. 1, 1972, pp. 113-120. doi:10.1080/0022250X.1972.9989806

[22] X. Qi, et al., "Terrorist Networks, Network Energy and Node Removal: A New Measure of Centrality Based on Laplacian Energy,” Social Networking, Vol. 1, No. 1, 2013, pp. 19-31. doi:10.4236/sn.2013.21003

[23] M. Lopes, "Good Vibrations: The Social Networks of Optimists and Alter-Optimists,” Social Networking, Vol. 1, No. 1, 2012, pp. 1-12. doi:10.4236/sn.2012.11001

[24] R. Xerez, P. Figueiredo and M. Silva, "Social Networks and Computer Mediated Communication: The Emerging of a Social Structure in a Portuguese Bank.” In M. M. Cruz-Cunha, et al., Eds., Handbook of Research on Business Social Networking: Organizational, Managerial, and Technological Dimensions, IGI Global, Hershey, 2011, pp. 727-737. doi:10.4018/978-1-61350-168-9.ch038 